\title{
Intra-industry trade and business cycles in ASEAN
}

\author{
Carlos Cortinhas \\ University of Minho-Economic Policies Research Unit (NIPE), \\ Braga, Portugal \\ E-mail: ccortinhas@eeg.uminho.pt
}

\begin{abstract}
A new resolve for both increased economic integration and monetary and exchange rate cooperation has started to emerge in the Association of Southeast Asian Nations (ASEAN), especially since the 1997-1998 Asian financial crisis. According to the optimum currency area theory, the degree of trade integration is one of the most important criteria for joining a currency union. The large increase in intra-ASEAN trade in recent years raises the question of whether the ASEAN countries are becoming better prepared to form a currency union. This article sets to test whether the recorded increase in intra-ASEAN trade is leading the ASEAN members to closer economic integration and thus to better satisfy the criteria for a common currency. Two separate models are estimated for that purpose. First, a variation of the model of Frankel and Rose (1997) was estimated for the ASEAN members. Next, a new panel data methodology was conducted. The results with our own model were very significant and robust when four of the ASEAN5 countries were considered, and showed a clear positive correlation between intra-industry trade and business cycle synchronization in ASEAN. This result has important implications for the prospects of the creation of a common currency in the region.
\end{abstract}

\section{Introduction}

The Association of Southeast Asian Nations (ASEAN) was established in Bangkok in 1967 and even if it seems unquestionable that it has been successful in containing intra-ASEAN conflicts and in providing a forum for the discussion of regional matters, it also seems consensual that ASEAN has failed in asserting itself as a political force on the world stage and has been disappointing in terms of tangible economic benefits for its members. ${ }^{1}$ This has led some authors to describe ASEAN as an enigma in Asia because of its longevity as a trading block which is always at the crossroads in the sense that it fails to deliver and periodically something always needs to be done to revitalize the integration process'. ${ }^{2}$

Recently, however, a new resolve for both increased economic integration and monetary and exchange rate cooperation has started to emerge, especially since the 1997-1998 Asian financial crisis.

\footnotetext{
${ }^{1}$ A recent paper by Lim and McAleer (2004), for example, using several different techniques did not find clear evidence of any income convergence and catching up in ASEAN suggesting that the existing gaps are not closing with time. It must be said, however, that since their data only covers the years from 1966 to 1992, that the opposite might be true after that period, especially since the introduction of Asean Free Trade Area (AFTA).

${ }^{2}$ Wilson (2002), p. 6. Pomfret (1996) is the author of the 'always at the crossroads' argument. The original five members of ASEAN or ASEAN5, Indonesia, Malaysia, Philippines, Singapore and Thailand have since been joined by Brunei Darussalam (in 1984), Vietnam (in 1995), Laos and Myanmar (in 1997) and Cambodia (in 1999).
} 
In fact, and paradoxically, the Asian financial crisis increased economic disparities within the region making monetary integration more difficult while at the same time, by showing the flaws of unilateral exchange rate pegging, worked as a 'wake up call for ASEAN $^{3}$ which increased the interest in a common currency arrangement for the region. ${ }^{4}$ In fact, a full currency union in ASEAN has become an inevitability for some of the most 'OCA-philes', at least in the long run. ${ }^{5}$ The recent popularity of the 'hollowing-out' hypothesis seems to leave no choice for ASEAN but to decide between fully flexible exchange rates or a common currency. ${ }^{6}$

Even though there has been a large increase in intra-regional trade in ASEAN since the beginning of the 90s it is not clear that it occurred as a direct effect of the tariff reduction or a more general trend in the world markets. ${ }^{7}$ It does, nevertheless, raise the question of whether the large increased Intra-Asean Trade in recent years is creating more harmonized business cycles amongst its members since in light of the existing literature on optimum currency areas (OCA) these are two of the most important criteria on the suitability of adopting a currency union (or other fixed or semi-fixed currency arrangements).

The degree of trade integration is believed to be an important OCA argument since it affects the likelihood of asymmetric shocks and their transmission between countries. The effect of more trade between two countries on the harmonization of business cycles is not, however, clear cut in the existing economic theory. Kenen (1969) was the first to suggest that well-diversified economies, having a large share of intra-industry trade (IIT) in their total trade, will experience less asymmetric shocks. Conversely, Krugman $(1991,1993)$ warned that the potential for asymmetric shocks increases with greater integration among countries (and regions) since it increases their specialization. These two opposing views on what would be the effect of closer integration on regional specialization (and thus on the costs and benefits of joining an OCA) are what came to be known as 'The European Commission View' and 'The Krugman View'.

The European Commission view states that closer integration will lead to a situation whereby asymmetric shocks will occur less frequently. The reasoning is that since most trade between European countries is IIT, the more integrated they are, the more similarly they will be affected by disturbances and therefore the more synchronized their business cycles will be. Conversely, Krugman's view, taking the United States as an example, is that increased integration leads to increased regional concentration of industries (in order to profit from economies of scale) and thus more trade will lead to more divergence between countries.

The ambiguity in the economic theory on this matter has made this an essentially empirical matter. In two seminal articles, Frankel and Rose (1997, 1998) argue that closer trade relations result in a convergence of business cycles, i.e. both international trade patterns and international business cycles correlations are jointly endogenous and thus that any monetary union creates ex-post an optimum currency area. ${ }^{9}$ Frankel and Rose report a significant and positive correlation between trade intensity and the correlation of business cycles as measured by four separate indicators of economic activity in a cross-section of Organization for Economic Cooperation and Development (OECD) countries between 1959 and 1993. Kenen (2000) argues that Frankel and Rose's results should be interpreted cautiously. He shows in a framework of the Keynesian model that the correlation between two countries' output changes increases unambiguously with the intensity of trade links between these

\footnotetext{
${ }^{3}$ Yong (2004), p. 2.

${ }^{4}$ Notable initiatives to promote regional financial stability and monetary policy cooperation include the establishment of 'Manila Framework Group' in 1997, the 'ASEAN Surveilance Process' in 1998 and the 'Chiang Mai Initiative' in 2000. Recent initiatives to promote economic integration include the ASEAN Free Trade Area (1992) and the adoption of the so-called 'ASEAN's Vision 2020' in 1997 where a timetable was established to create an ASEAN Economic Region.

${ }^{5}$ Recently Mundell (2001), defended that Asia eventually needs a common currency even though it recognized that it cannot at present have a single currency, p. 18.

${ }^{6}$ See Eichengreen (1999) and Wyplosz (2001).

${ }^{7}$ Sharma and Chua (2000) found empirical evidence that the 'ASEAN integration scheme did not increase intra-ASEAN trade' and that 'increase in ASEAN countries trade occurred with members of a wider APEC group', p. 167. A more recent study by Elliot and Ikemoto (2004) reinforce these findings and even come to the conclusion that the degree of trade creation in the years immediately after the signing of the AFTA agreement in 1993 was actually lower than for the preceding period of 1988 to 1992.

${ }^{8}$ De Grauwe (1997) was the first to use these denominations. The first accrues from European Commission (1990) and the second from Krugman (1991, 1993). Patterson and Amati (1998) quote Peters (1995) as dividing the same opposite approaches as the 'Convergence School' and the 'Divergence School'.

${ }^{9}$ They conclude that 'a naïve examination of historical data gives a misleading picture of a country's suitability for entry into a currency union, since the OCA criteria are endogenous', (1998, p. 1010).
} 
countries but this does not necessarily mean that asymmetric shocks are reduced as well.

A number of recent empirical studies seem to confirm a positive correlation between IIT and business cycles synchronization, and that increased trade itself does not necessarily lead to business cycle harmonization. Firdmuc (2004) found that when Frankel and Rose's model was augmented to include IIT there was no relation between business cycles and trade intensity. Intra-industry trade, however, was found to have a positive and significant relationship with business cycles for the OECD countries between 1990 and 1999. Shin and Wang (2003), applying a model which included a larger set of explanatory variables found that IIT is the major channel through which the business cycles of 12 East Asian economies become synchronized and that increasing trade itself does not necessarily lead to greater synchronization of business cycles. Gruben et al. (2002) show the instrumental variables used by Frankel and Rose in their study to be inappropriate and to result in inflated results. They develop an Ordinary Least Square (OLS)-based procedure adding structure-oftrade variables to the model to separate the effects of intra- and inter-industry trade and to include a number of omitted variables for the countries. Their findings are consistent with Frankel and Rose's and conclude that specialization does not asynchronise business cycles between the OECD countries.

These recent empirical contributions suggest that the effect of more trade between two countries on the harmonization of business cycles depends not only on the intensity of trade links but on the structure of that trade. If more trade means more IIT, we should expect more common shocks and thus, more business cycle harmonization. If, however, more trade means more specialization, we should expect more idiosyncratic shocks.

The contribution of this article is to test this hypothesis in the special case of ASEAN, that is, to investigate whether the recorded increase in intra-ASEAN trade in recent years, measured at the highly disaggregated 4-digit industry level, is leading the ASEAN members to closer economic integration and thus creating better preconditions for policy integration and the creation of a common currency area. As will be discussed subsequently, there is a lack of consensus on the correct methodology to use for this purpose and therefore several methods are employed.

The article is structured as follows: Section I will explain the data and empirical methodology and present the empirical results. Finally, Section II concludes the article.

\section{Data, Empirical Methodology and Results}

To measure output co-movements, annual data on real GDP was collected for the ASEAN5 countries over the period 1962-1996 from the IMF International Financial Statistics CD-ROM. The period after 1997 is excluded because the data is likely to be distorted by the 1997-1998 Asian Financial Crisis. ${ }^{10}$ Data on the other ASEAN countries was not available and therefore these countries were excluded from this study.

Intra-Industry Trade in ASEAN was measured using the traditional Grubel-Lloyd (1975) Index. The IIT indexes were computed for all industries over the period 1962-1996 using the 'World Trade Flows, 1962-2000' data complied by Feenstra et al. (2005) at the 4-digit industry classifications following the Standard International Trade Classification (SITC), revision $2 .{ }^{11}$

Since there is no consensus on the correct methodology to apply, several models will be tested. First, the variation of Frankel and Rose's (1997) model first applied by Firdmuc (2004) will be estimated:

$$
\operatorname{Corr}\left(Q_{i}, Q_{j}\right)=\alpha+\beta \mathrm{IIT}_{i j}+\varepsilon
$$

where $\operatorname{Corr}\left(Q_{i}, Q_{j}\right)$ stands for the correlation of de-trended real GDP and $\operatorname{IIT}_{i j}$ denotes the average 4-digit level of IIT index between ASEAN5 countries $i$ and $j$ in each period and $\varepsilon$ is the error term. ${ }^{12}$ The sign of the coefficient $\beta$ if negative will indicate that the specialization effect dominates in ASEAN ('Krugman View') and if positive will mean that more IIT leads to more

\footnotetext{
${ }^{10}$ In any case, a recent study by Zhang et al. (2004) found evidence that the Asian Financial crisis has increased the degree of supply, demand and monetary shock correlation among ASEAN countries. Therefore, the exclusion of this period from the analysis should not overstate the results.

${ }^{11}$ Originally, this study intended to include not only the Grubel and Lloyd (1975) IIT index but also the measures developed by Abd-el-Rahman (1991) and Fontagné and Freudenberg (1997) for vertical and horizontal intra-industry trade. That was not possible; however, as the sample included a significant number of zero observations which would greatly limit the analysis. ${ }^{12}$ Originally, Frankel and Rose (1997) used the model $\operatorname{Corr}\left(Q_{i}, Q_{j}\right)=\alpha+\beta \mathrm{TI}_{i j}+\varepsilon$, where $\mathrm{TI}_{i j}$ stands for trade intensity between countries $i$ and $j$. They used four de-trending methods for real GDP and three other measures of economic activity and three measures of trade intensity, defined in relation to exports, imports and trade turnover.
} 
output synchronization in that region (European Commission View). As stated earlier, most empirical evidence to date seems to be consistent with the latter possibility so that we expect a positive coefficient for IIT. ${ }^{13}$

Frankel and Rose (1997) note that countries are likely to orient their monetary policy and fix exchange rates towards their most important trade partners. In the case of ASEAN it is well known that the US dollar has a large weight in the exchange rate policies leading them to pursue broadly similar monetary policies. As noted by Firdmuc (2004), it is quite possible that bilateral trade reflects the adoption of a common exchange rate policy and not vice-versa. This suggests the need to instrument the regressions by exogenous determinants of intra-industry trade. The instruments normally chosen for the two-stage least squares (TSLS) are the ones provided by the gravity models and include the log of distance between countries and a dummy for geographic adjacency. ${ }^{14}$ However, Gruben et al. (2002) suggested that these instruments might be inappropriate and result in inflated results. However, the authors also find when using an alternative OLS-based approach, that their results are consistent with those of Frankel and Rose's model. Accordingly, the results for both OLS and TSLS are presented for (1).

Following Frankel and Rose (1997), the whole sample period is divided into four subsample periods: 1962-1970, 1971-1979, 1980-1988 and 1989-1996 in order to access time-series changes in IIT patterns and business cycles correlations. As there is no consensus on the proper de-trending method to apply, the four alternative methods of de-trending real GDP first applied by Frankel and Rose (1997) namely, first-differencing, HP-filtering, quadratic de-trending and HP-filtering on the residual of a regression of the real GDP on a constant and 5-year period dummies, were used. ${ }^{15}$ Since the sample includes five countries, the number of observations will be 40 (10 country pairs each with four period observations).

Table 1 reports the results of eight separate specifications, corresponding to the four de-trending methods discussed earlier, applied to both OLS and TSLS estimations. ${ }^{16}$

The results are very weak. Even though IIT yielded the expected sign in all specifications, it was found to be significant (and only marginally so) in only one case.

Also, as expected, the TSLS versions of (1) generate more robust results than the OLS estimates. However, the question of whether the variables used as instruments are valid instruments, i.e. uncorrelated with the error term, might cast some doubt on the results.

In order to investigate this matter, a procedure developed by Baum et al. (2003) is applied that allows for the determination of the Hansen test of overidentifying restrictions in TSLS. ${ }^{17}$ The results are presented in Table 2.

The Hansen test included a specification that takes into account the possibility that observations might not necessarily be independent within the group of countries under analysis. As the null hypothesis of the Hansen test is that the instruments are valid, i.e. the instruments are uncorrelated with the error term, the instruments can reasonably be accepted as being valid in all four specifications. Once again only one specification was found to be significant but in this case corresponds to the estimation of (1) using first-differenced de-trended data [specification (1)] instead of the estimation using quadratic de-trending data [specification (3)] in Table 1. To all effects, the size of the estimated coefficient $\beta(0.01)$ is much smaller than the results reported by Firdmuc (2004) for the OECD countries $(0.175)^{18}$ using a similar methodology. The extremely low values of the $R$-squares suggest that there are other factors beyond IIT - like demand shocks - producing business cycle harmonization, generating a problem of omitted variables.

\footnotetext{
${ }^{13}$ This is especially true as the specialization effect is more likely to exist in terms of inter-industry trade than IIT.

${ }^{14}$ These two variables are known to be highly correlated with IIT (see for example Loertscher and Wolter, 1980 and Hummels and Levinsohn, 1995). Both shorter distance and common border are expected to increase intra-industry trade for three main reasons, lower transportation costs, cultural similarities and similar resource bases which increases the likeliness of countries to participate in the same industries.

${ }^{15}$ Unlike Frankel and Rose (1997) the data frequency in the present study is annual. Therefore, some adjustments needed to be made, namely, first differencing instead of fourth-differencing and the use of 5-year period dummies instead of quarterly dummies for the quadratic de-trending and HP-filtering of a regression of real GDP on a constant and period dummies.

${ }^{16}$ All estimations were conducted with Stata version 8.2 .

${ }^{17}$ Baum et al. (2003) developed a STATA module called ivreg2 for extended TSLS estimation and instrument validity testing.

${ }^{18}$ Firdmuc (2004) however, uses quarterly instead of annual data which might account for some of the difference. Also, in his study the IIT indexes were computed for three-digit SITC commodity groups. Immediate conclusions should, therefore, be avoided.
} 


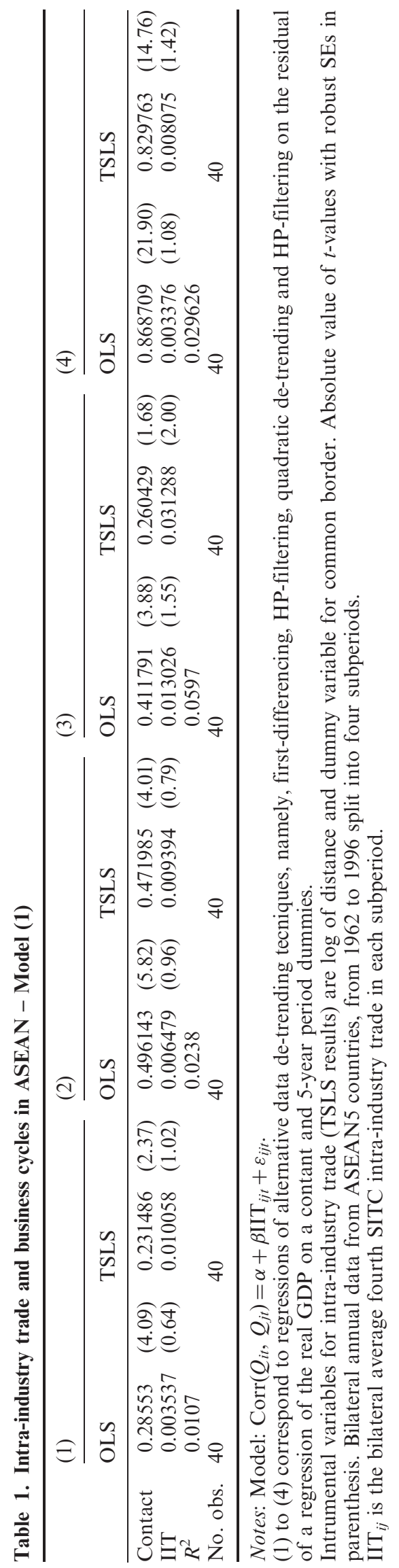


Table 2. Hansen tests to the validity of the instruments of Model (1)

\begin{tabular}{llllc}
\hline & $(1)$ & $(2)$ & (3) & (4) \\
& TSLS & TSLS & TSLS & TSLS \\
\hline Contant & $0.231486(3.78)$ & $0.4719848(4.95)$ & $0.2604285(1.46)$ & $0.829763(16.49)$ \\
IIT & $0.0100578(2.34)$ & $0.0093942(1.21)$ & $0.0312887(1.68)$ & $0.0080749(1.51)$ \\
Hansen $J$-statistic & 1.467 & 1.036 & 2.492 & 2.221 \\
Chi-Square $(1) p$-value & 0.226 & 0.308 & 0.114 & 0.136 \\
No. obs. & 40 & 40 & 40 & 40 \\
\hline
\end{tabular}

Notes: Model: $\operatorname{Corr}\left(Q_{i}, Q_{j}\right)=\alpha+\beta \mathrm{IIT}_{i j t}+\varepsilon_{i j t}$.

(1) to (4) and IIT assume the same meaning as in Table 1.

Intrumental variables for intra-industry trade (TSLS results) are log of distance and dummy variable for common border.

Absolute value of $t$-values with robust SEs to both heteroskedasticity and arbitrary intra-group correlation in parenthesis.

The division of the sample period into subperiods in (1) raises a number of important issues. First, by creating subperiods, we are in fact using small period averages of the variables which greatly reduces the number of observations in the estimations and its explanatory power which creates an error in variable (EIV) problem, especially when using annual data. Second, the division of the whole sample period into four more or less arbitrary periods raises the question of whether these smaller periods are able to capture the business cycles. Finally, as the analysis below will demonstrate, the explanatory variable is nonstationary and since this issue is not addressed in (1) the results may in fact be spurious.

In order to try to overcome these problems, the following model is estimated:

$$
\left(\Delta Q_{i}-\Delta Q_{j}\right)^{2}=\alpha+\beta \Delta \mathrm{IIT}_{i j}+\varepsilon
$$

where $Q_{i}, Q_{j}, \mathrm{IIT}_{i j}$ and $\varepsilon$ assume the same meaning as in (1). This alternative model has the great advantage of using yearly data and therefore of greatly increasing the number of observations. Since (2) is to be estimated using panel data, for the results to be valid both the dependent variable and the regressor need to be stationary. For that purpose, several alternative unit root tests were conducted for both variables. The results are presented in the Appendix.

First, a Fisher-type unit root test for panel data, developed by Madalla and Shaowen (1999) was conducted for the variable IIT using both an augmented Dickey-Fuller (ADF) test and a Phillips-Peron (PP) test. This test assumes that all series are nonstationary under the null hypothesis against the alternative that at least one series in the panel is stationary. Table A1 of the Appendix reports the results. The results show that we cannot reject the hypothesis that all 10 individual time series contain unit roots.
As there seems to be no agreement on the validity of panel unit root tests, $\mathrm{ADF}$ and PP tests were also conducted for all individual IIT time-series in first-differences. The tests were conducted with one lag and a constant and a trend in the test regressions for the cases where a trend was found to be significant and only a constant for the remainder cases. Table A2 of the Appendix presents a summary of the results and shows all series to be integrated of order 1 at the $1 \%$ level of confidence in at least one of the tests. The results presented in Tables A1 and A2 show that we can reasonably assume the first-difference of the variable IIT to be stationary.

Next, we look at the dependent variable. Once again both the ADF test and the PP test were regressed for all individual series of the dependent variable, using three alternative data de-trending methods, namely, HP-filtering, quadratic-de-trending and HP-filtering on the residual of a regression of the real GDP on a constant and 5-year period dummies. ${ }^{19}$ The results are presented in Table A3 of Appendix A. The dependent variable was found to be stationary in two data de-trending methods, namely quadratic de-trending and HP-filtering on the residual of a regression of the real GDP and 5-year period dummies. However, the dependent variable de-trended by HP-filtering was found to be nonstationary in both tests in at least three individual time series. Accordingly, regressions of (2) will only be conducted using the two series found to be stationary.

Due to the construction of the model, the sign of $\beta$ now assumes the opposite significance of the previous models, that is, a negative sign implies that an increase in intra-industry trade will reduce differences in the growth rate of business cycles across ASEAN countries.

As stated before, OLS estimations of (2) may be inappropriate in this case. Therefore, the regressions

\footnotetext{
${ }^{19}$ First-differencing of the data was excluded as it did not, in this case, remove the trend in the data.
} 
Table 3. Intra-industry trade and business cycles in ASEAN - Model (2)

(1)

(2)

\begin{tabular}{lcc}
\hline Contant & $13.83819(2.64)$ & $37.08033(2.23)$ \\
$\Delta$ IIT & $-16.03203(1.92)$ & $-45.78226(1.75)$ \\
Hansen $J$-statistic & 0.165 & 0.218 \\
Chi-Square(1) $p$-value & 0.68 & 0.64 \\
No. obs. & 340 & 340 \\
\hline
\end{tabular}

Notes: Model: $\left(\Delta Q_{i t}-\Delta Q_{j t}\right)^{2}=\alpha+\beta \mathrm{IIT}_{i j t}+\varepsilon_{i j t}$.

(1) and (2) correspond to regressions of two alternative data de-trending tecniques, namely, quadratic-detrending and HP-filtering on the residual of a regression of the real GDP on a constant and 5-year period dummies.

Intrumental variables for intra-industry trade are log of distance and a dummyfor common border.

Absolute value of $t$-values in parenthesis with robust standard errors to both heteroskedasticity and arbitrary intra-group correlation.

Table 4. Estimations for Model (2) with year dummies as instruments

\begin{tabular}{lll}
\hline & (1) TSLS & (2) TSLS \\
\hline Contant & $9.212954(0.38)$ & $25.49597(0.37)$ \\
$\Delta$ IIT & $-16.03203(1.82)$ & $-45.78226(1.66)$ \\
No. obs. & 340 & 340 \\
\hline
\end{tabular}

Notes: Model: $\left(\Delta Q_{i t}-\Delta Q_{j t}\right)^{2}=\alpha+\beta \operatorname{IIT}_{i j t}+\varepsilon_{i j t}$.

(1) and (2) assume the same meaning as in Table 3.

Intrumental variables for intra-industry trade are log of distance, a dummy for common border and dummies for each year (minus one) of the sample data.

Absolute value of $t$-values with robust SEs in parenthesis.

of (2) will be estimated by TSLS using the same instruments used in (1) as they proved to be valid in that case. Table 3 shows the results for the TSLS estimates of (2) which also included a specification that takes into account the possibility that observations might not necessarily be independent within the group of countries under analysis.

The coefficient of IIT yielded the expected sign in both specifications suggesting that the increase in intra-ASEAN trade has led to more synchronized business cycles amongst its members. The coefficients for IIT were not, however, were not found to be very significant with only one (specification 1) being significant at the $10 \%$ level.

As before, the Hansen test was estimated and included a specification that takes into account the possibility that observations might not necessarily be independent within the group of countries under analysis. The results show that once again the instruments used can be considered valid as we cannot reject the null hypothesis that the instruments are uncorrelated with the error term.
Table 5. Estimations for (2) using alternative combinations of 4 of the ASEAN5

(1)

(2)

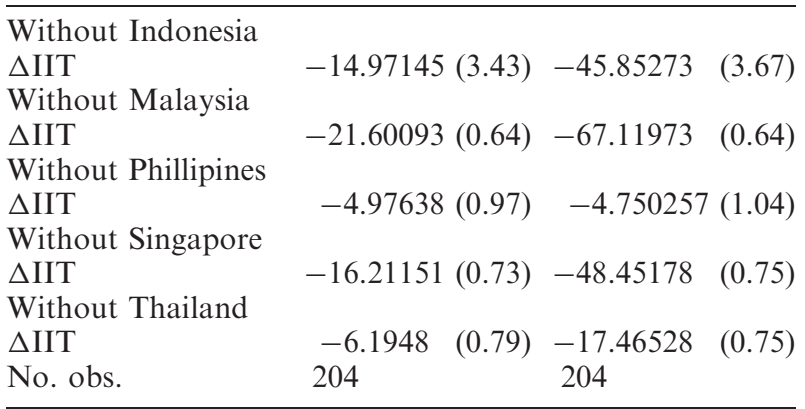

Notes: Model: $\left(\Delta Q_{i t}-\Delta Q_{j t}\right)^{2}=\alpha+\beta \mathrm{IIT}_{i j t}+\varepsilon_{i j t}$.

(1) and (2) assume the same meaning as in Table 3. Constants not reported.

Intrumental variables for intra-industry trade are log of distance and a dummy for common border and dummy variables for each year (minus one) of the sample data.

Absolute value of $t$-values in parenthesis with robust standard errors to both hetero skedasticity and arbitrary intra-group correlation.

In order to further test the robustness of the results, the same two specifications of (2) were estimated using as instruments not only the log of distance and a dummy for common border but also dummies for each period (minus one) of the whole sample period. Table 4 presents the results.

The results are identical with those of Table 3 . Once again, the coefficients for IIT was not found to be significant.

Finally, in order to access the possible influence of one individual country in the results of the whole group, (2) was estimated excluding all the data involving each of the countries with the remaining pairs, that is, instead of including all of the five countries (10 pairs) in the sample, five separate regressions using the data of four countries (6 pairs) were computed. In these TSLS estimations, apart from the $\log$ of distance and a dummy for land border, dummies for each year (minus one) of the data sample were also included. The results are presented in Table 5.

Excluding one country from the sample does not significantly change the previous outcome with one notable exception. When Indonesia is excluded from the sample, the coefficient of IIT becomes significant at the $1 \%$ level in both specifications. The explanation for this result might be that because Indonesia is the largest and relatively more closed economy of the group it is less integrated with the rest of ASEAN than its smaller and more open partners. 
Furthermore, these results also show that the recorded increase of IIT amongst Malaysia, the Philippines, Singapore and Thailand has led to the synchronization of business cycles among its members. This result is consistent with previous empirical studies in confirming the 'European Commission View'. ${ }^{20}$

\section{Final Remarks}

Frankel and Rose $(1997,1998)$ found that business cycles synchronization increases with trade intensities leading them to conclude that these two important OCA criteria - trade links and similarity of business cycles - are jointly endogenous. This argument is a source of contention and can be interpreted as an invitation to disregard the 'static' OCA theory and encourage the early introduction of a monetary union since a country is more likely to satisfy the OCA criteria for entry into a currency union ex post than ex ante due to lowered asymmetrical shocks.

Recent empirical studies have shown, however, that increasing trade itself does not necessarily lead to more synchronization of business cycles. The effect of more trade between two countries on the harmonization of business cycles depends not only on the intensity of trade links but on the structure of that trade. More trade will mean more synchronized business cycles only if it is of the intra-industry type, as we should expect more common shocks across countries. Otherwise, more trade might mean more specialization, and we should expect more idiosyncratic shocks.

This article sets to test whether the recorded increase in intra-ASEAN trade is leading the ASEAN members to closer economic integration and thus to better satisfy the criteria for a common currency. Two separate models are estimated for that purpose. First, a variation of the model of Frankel and Rose (1997) first used by Firdmuc (2004) was estimated for the ASEAN members. Following Frankel and Rose (1997) four alternative data de-trending techniques were applied in both OLS and TSLS regressions. The results were very weak, with only one specification out of eight being statistically significant even if all the results yielded the expected positive relation between IIT and the synchronization of business cycles. Furthermore, this methodology has some flaws which may invalidate the results.
Therefore, a new methodology was implemented. Unlike previous studies, our own panel data model uses the whole sample data instead of dividing it into sub-groups which greatly increases the number of observations in the regressions. The results with our own model for ASEAN5, using two alternative data de-trending techniques suggested a positive correlation between IIT and business cycle synchronization in ASEAN but were not very significant. However, when excluding Indonesia from the sample, the result becomes highly significant for both data de-trending methods. The results are very robust even when using the highly disaggregated SITC fourth-digit industry data for all reported trade unlike most previous studies that either use the three-digit level of data aggregation (Frankel and Rose, 1997, 1998; Gruben et al., 2002; Firdmuc, 2004) or a limited number of industries (Shin and Wang, 2003). Also, it was shown that the instruments used in the two-stage least squares of both models included in this article - log of distance and a dummy for a geographic adjacency - to be valid, which further strengthens our conclusions. This outcome contrasts with Gruben et al. (2002) which report the instrumental variables used by Frankel and Rose in their study to be inappropriate and to result in inflated results.

These results have important implications for the prospects of the creation of a common currency in ASEAN. As IIT leads to business cycle synchronization with respect to Malaysia, the Philippines, Singapore and Thailand, the costs of joining a currency union in ASEAN will diminish when IIT is dominant. Therefore, even if we take the endogenous OCA criteria hypothesis as valid - that a monetary union creates ex-post an OCA - the traditional OCA theory is still relevant since observing the initial conditions for a potential monetary union will give us an idea of how costly it would be for each member and how the economic policy can decrease the adjustment costs.

\section{Acknowledgements}

The author is grateful to Francisco Veiga and Miguel Ângelo of The University of Minho and John Maloney, Malcolm Macmillen and Cherif Guermat of The University of Exeter for useful comments and suggestions. The usual disclaimer applies.

\footnotetext{
${ }^{20}$ It should be noted that this is not necessarily a rejection of 'Krugman's View'. The specialization effect is more likely to exist as regards to inter-industry trade than for IIT.
} 


\section{References}

Abd-el-Rahman, K. (1991) Firms' competitive and national comparative advantages as joint determinants of trade composition, Weltwirtschaftliches Archive, 127, 83-97.

Baum, C., Schaffer, M. and Stillman, S. (2003) Instrumental variables and GMM: estimation and testing, The Stata Journal, 3, 1-31.

De Grauwe, P. (1997) The Economics of Monetary Integration, 3rd edn, Oxford University Press, London.

Eichengreen, B. (1999) Toward a New Financial International Architecture: a Practical Post-Asia Agenda, Institute for International Economics, Washington, DC.

Elliot, R. and Ikemoto, K. (2004) AFTA and the Asian crisis: help or hindrance to ASEAN intra-regional trade?, Asian Economic Journal, 18, 1-23.

European Commission (1990) One market, one money: an evaluation of the potential benefits and costs of forming an economic and monetary union, European Economy, October, 44.

Feenstra, R., Lipsey, R., Deng, H. and Ma, A. (2005) World trade flows, 1962-2000, NBER Working Paper 11040 .

Firdmuc, J. (2004) The Endogeneity of the optimum currency area criteria, intra-industry trade, and EMU enlargement, Contemporary Economy Policy, 22, 1-12.

Fontagné, L. and Freudenberg, M. (1997) Intra-industry trade: methodological issues, document de travail CEPII, 97-01.

Frankel, J. and Rose, A. (1997) Is EMU more justifiable ex post than ex ante?, European Economic Review, 41, 753-60.

Frankel, J. and Rose, A. (1998) The Endogeneity of the optimum currency area criteria, The Economic Journal, 108, 1009-25.

Grubel, H. G. and Lloyd, P. J. (1975) Intra-Industry Trade, Macmillan, London.

Gruben, W., Koo, J. and Millis, E. (2002) How much does international trade affect business cycle synchronization, Federal Reserve Bank of Texas Research Department Working Paper 0203.

Hummels, D. and Levinsohn, J. (1995) Monopolistic competition and international trade: reconsidering the evidence, Quarterly Journal of Economics, 110, 799-836.

Kenen, P. B. (1969) The Theory of optimum currency areas: an eclectic view, in Monetary Problems in the International Economy (Eds) R. Mundel and A. Swoboda, University of Chicago Press, Chicago, pp. 41-60.

Kenen, P. B. (2000) Currency areas, policy domains and the institutionalization of fixed exchange rates, CEP Discussion Papers, 0467.
Krugman, P. R. (1991) Geography and Trade, MIT Press, Cambridge, Massachusetts.

Krugman, P. R. (1993) Lessons from massachusetts for EMU, in Adjustment and Growth in the European Monetary Union (Eds) F. Torres and F. Giavazzi, Cambridge University Press, Cambridge, pp. 241-69.

Lim, L. K. and McAleer, M. (2004) Convergence and catching up in ASEAN: a comparative analysis, Applied Economics, 36, 137-53.

Loertscher, R. and Wolter, F. (1980) Determinants of intra-industry trade: among countries and across industries, Weltwirtschaftliches Archiv, 116, 280-93.

Maddala, G. S. and Shaowen, W. (1999) A comparative study of unit root tests with panel data and a new simple test, Oxford Bulletin of Economics and Statistics, 61, 631-52.

Mundell, R. (2001) Poverty, Growth and the International Monetary System, Paper Presented at the ADB Seminar 'Asia and Pacific Forum on Poverty: Reforming Policies and Institutions for Poverty Reduction', Manila, February.

Patterson, B. and Amati, S. (1998) Adjustment to asymmetric shocks, Directorate-General for Research Working Paper, Economic Affairs Series, ECON-104.

Peters, T. (1995) European monetary union and labour markets: what to expect?, International Labour Review, 134, 315-32.

Pomfret, R. (1996) ASEAN - Always at the crossroads?, Journal of the Asia Pacific Economy, 1, 365-90.

Sharma, S. C. and Chua, S. Y. (2000) ASEAN: economic integration and intra-regional trade, Applied Economic Letters, 7, 165-9.

Shin, K. and Wang, Y. (2003) Trade integration and business cycle synchronisation in east Asia, ISER Discussion Paper 574.

Wilson, P. (2002) Prospects for Asian monetary cooperation after the Asian financial crisis: pipedream or possible reality?, National University of Singapore Working Paper 151.

Wyplosz, C. (2001) A Monetary union in Asia? Some European lessons, RBA Annual Conference Volume 2001-08, Reserve Bank of Australia.

Yong, O. K. (2004) Towards ASEAN Financial Integration, remarks by the Secretary-General of ASEAN at the Economix 2004 Conference, University of Jakarta, February 18, Typescript available for download at http://www.aseansec.org/ 16014.htm

Zhang, Z., Sato, K. and McAleer, M. (2004) Is a monetary union feasible for east Asia?, Applied Economics, 36, 1031-43. 


\section{Appendix: Unit Root Tests}

Table A1. Fisher test for panel unit root on variable IIT in levels

\begin{tabular}{llr}
\hline & ADF & \multicolumn{1}{c}{ PP } \\
\hline Chi-square (20) & 4.9758 & 10.7516 \\
Prob. > Chi-square & 0.9997 & 0.9524 \\
\hline
\end{tabular}

Notes: $\mathrm{ADF}=$ Augmented Dickey-Fuller test, $\mathrm{PP}=$ Phillips-Perron test.

The number of lags set at one in both cases.

$\mathrm{H}_{0}$ : Unit root in all series.

Table A2. Unit root tests for all individual IIT series in first-differences

\begin{tabular}{llr}
\hline Pair & ADF & PP \\
\hline Indonesia-Singapore & $-6.334^{*}$ & $-11.325^{*}$ \\
Indonesia-Malaysia & $-7.292^{*}$ & $-6.970^{*}$ \\
Indonesia-Phillipines & $-3.975^{*}$ & $-5.564^{*}$ \\
Indonesia-Thailand & -2.736 & $-5.530^{*}$ \\
Malaysia-Phillipines & $5.495^{*}$ & $-8.532^{*}$ \\
Singapore-Malaysia & $-6.144^{*}$ & $-7.472^{*}$ \\
Thailand-Malaysia & -3.860 & $-4.709^{*}$ \\
Thailand-Phillipines & $-4.101^{*}$ & $-7.626^{*}$ \\
Thailand-Singapore & -2.343 & $-4.635^{*}$ \\
Singapore-Phillipines & $-3.899^{*}$ & $-8.374^{*}$ \\
\hline
\end{tabular}

Notes: $\mathrm{ADF}=$ Augmented Dickey-Fuller test statictics, $\mathrm{PP}=$ Phillips-Perron test statistics.

The estimations included a trend in the cases when a trend was found to be significant at the $5 \%$ level.

* Rejection of hypothesis of unit root at $1 \%$ critical level.

Table A3. Unit root tests for all individual series of depended variable of (2)

\begin{tabular}{|c|c|c|c|c|c|c|}
\hline \multirow[b]{2}{*}{ Pair } & \multicolumn{2}{|l|}{ (1) } & \multicolumn{2}{|l|}{ (2) } & \multicolumn{2}{|l|}{ (3) } \\
\hline & $\mathrm{ADF}$ & $\mathrm{PP}$ & $\mathrm{ADF}$ & PP & $\mathrm{ADF}$ & PP \\
\hline Indonesia-Singapore & -1.207 & -1.641 & $-5.057^{*}$ & $-3.636^{* *}$ & $-3.827 * *$ & $-3.900 *$ \\
\hline Indonesia-Malaysia & $-3.515 * *$ & $-4.336^{*}$ & $-3.732 *$ & $-4.176^{*}$ & $-3.899 *$ & $-5.584 *$ \\
\hline Indonesia-Phillipines & -1.207 & -1.641 & $-3.487 * *$ & $-4.627 *$ & $-3.519 * *$ & $-5.501 *$ \\
\hline Indonesia-Thailand & $-3.332 * *$ & $-4.202 *$ & $-3.729 *$ & $-5.717 *$ & $-5.083^{*}$ & $-6.541 *$ \\
\hline Malaysia-Phillipines & -3.062 & $-4.985^{*}$ & $-3.547 * *$ & $-5.556^{*}$ & $-3.760^{*}$ & $-5.234^{*}$ \\
\hline Singapore-Malaysia & 0.212 & -1.643 & -2.336 & $-4.180^{*}$ & $-2.961 * * *$ & $-3.183 * *$ \\
\hline Thailand-Malaysia & $-3.674 * *$ & $-3.674 * *$ & $-2.845^{* * *}$ & $-4.506^{*}$ & $-2.992 * *$ & $-4.743 *$ \\
\hline Thailand-Phillipines & $-3.162 * *$ & $-3.419 * *$ & $-3.986^{*}$ & $-5.176^{*}$ & $-4.588^{*}$ & $-6.071^{*}$ \\
\hline Thailand-Singapore & $4.005 * *$ & $-6.660 *$ & $-2.823 * * *$ & $-5.446^{*}$ & $-3.724 * *$ & $-6.595 *$ \\
\hline Singapore-Phillipines & $-3.237 * *$ & $-5.194 *$ & $-3.811^{*}$ & $-5.454^{*}$ & $-3.650 * *$ & $-5.051^{*}$ \\
\hline
\end{tabular}

Notes: The estimations included trend in the cases where a trend was found to be significant at the $5 \%$ level.

$\mathrm{ADF}=$ Augmented Dickey-Fuller test statistics and PP $=$ Phillips-Perron test statistics.

(1) to (3) correspond to regressions of the dependent variable using alternative data de-trending techniques, namely, HP-filtering, quadratic-HP-filtering, detrending and HP-filtering on the residual of a regression of the real GDP on a constant and 5-year period dummies.

Significance level at which the null hypothesis is rejected: $* 1 \%, * * 5 \%$ and $* * * 10 \%$. 